\title{
Evaluation of Ophthalmic Surgical Injuries Presenting to an Ophthalmology Emergency Department
}

\author{
(1) Sema Yüzbașıoğlu¹, (1) Mücella Arıkan Yorgun¹, (1) Yücel Yüzbașıoğlu²
}

1Department of Ophthalmology, Yıldırım Beyazıt University, Ankara City Hospital, Ankara, Turkey

2Department of Emergency Medicine, University of Health Sciences Turkey, Gülhane Training and Research Hospital, Ankara, Turkey

\begin{abstract}
Aim: To determine the incidence and clinical characteristics of patients who presented with an ophthalmic emergency and required ophthalmic surgical intervention.

Materials and Methods: Patients who presented at our ophthalmology department with surgical ocular traumatic injuries from 2017 to 2018 were retrospectively examined. Information about demographic characteristics, details of the injury, diagnoses, examinations, and surgical procedures was obtained. The time between the occurrence of eye injury and presenting to the hospital and time of surgery were also recorded.

Results: Thirty-eight eyes of 35 patients [74\% males and 26\% females (mean age: $31 \pm 19)$ ] were included. Three cases were bilateral. The main causes of ocular surgical injuries were traffic accidents (15 eyes; 39\%), work accidents (11 eyes; 29\%), assault (five eyes; 13\%), and other causes (seven eyes; 18\%). The most frequent was eye penetrating injury (58\%). Most of the operations (33 eyes; 87\%) were performed on the first day of the injury, while the rest were performed between the first and tenth days. Twenty-eight eyes (74\%) underwent a single operation, while additional surgical procedures were necessary in 10 eyes (26\%). Twenty patients (57\%) were admitted to the ophthalmology service. There was an improvement in the visual acuity in 19 eyes (50\%), no change in 12 eyes (32\%), and worsening in seven eyes (18\%).

Conclusion: Surgery-requiring ophthalmologic injuries involve mainly males at younger ages, and traffic accidents are the most common cause of trauma. In $50 \%$ of these patients, an increase in the visual acuity was observed after surgery, so performing a correct surgery as early as possible can prevent visual impairment and blindness.
\end{abstract}

Keywords: Eye injuries, penetrating, emergencies, surgical procedures, operative

\section{Introduction}

Ocular trauma accounts for nearly $10 \%$ of all body traumas and is a major cause of visual loss. An estimated 55 million patients worldwide suffer from ocular trauma each year and approximately 1.6 million of them develop blindness because of the trauma (1).

Ocular trauma is one of the most frequent reasons for ophthalmology emergency department visits in the world and preventable cause of visual morbidity. So, continues to be an important public health problem in Turkey, too. Therefore, it is necessary to attach great importance to the emergency treatment of ocular trauma, and to adopt practical and effective methods.

Although the vast majority of ocular trauma is minor (such as superficial injury of the eye and adnexa, foreign body on external eye surface) and not related to permanent visual impairment, severe eye injuries often require surgical intervention and result in poor vision outcome (2-4). Especially in pediatric age groups, 
the most common cause of unilateral blindness is ocular trauma, especially in developing countries. And it is simply preventable by the supervision of the parents and baby caregivers (5).

Ocular injuries also may result in significant economic burdens to families and countries because of time lost from work or school, family care giving, expensive hospital costs, specialist visits and treatment, prolonged follow-up and visual rehabilitation (6).

Since any study based on ocular traumatic emergency is limited by the accuracy of the code used, regional differences, there is little reliable information on the incidence, severity, and etiologies of ocular surgical injuries in Turkey $(7,8)$.

Herein, we aim to determine the incidence and clinical characteristics of ophthalmic emergency cases who required ophthalmic surgical intervention.

\section{Materials and Methods}

\section{Study Protocols}

This study was a retrospective, observational study conducted at an urban hospital's ophthalmology emergency department. The study was approved by the Yıldırım Beyazıt University Faculty of Medicine Clinical Researches Ethics Committee (decree no: 118, date: 28/05/2018). Eligible participants included consecutive ocular trauma patients who underwent surgical management from February 2017 through January 2018. Data were collected from the Ophthalmology department medical records including demographic characteristics, mechanism of injury, diagnoses, best corrected visual acuity (BCVA) with Snellen chart, slit lamp exam findings and surgical procedures were obtained. The time period between the occurrence of eye injury and presentation to the emergency department and time to surgery were also recorded. Zone classification according to the Open-Globe Injury Classification was frequently absent from medical recordings so the location of injury was classified as corneal, scleral, or both (perilimbal lesions included) $(9,10)$.

Improvement in visual acuity defined as two lines or more increase in BCVA on the Snellen chart.

Patients who were admitted to the eye emergency department due to isolated ocular trauma and requiring surgical intervention and who were followed up regularly were included in the study. Eye trauma was classified according to the Birmingham Eye Trauma Terminology system (11) (Figure 1).

Patients with multiple traumas, patients with total visual loss before trauma or patients without enough medical records and follow-up after surgery were excluded from the study. The research was performed according to the tenets of the Declaration of Helsinki.

\section{Statistical Analysis}

Statistical analyses were performed using SPSS for Windows 18.0 (Chicago, IL) software package. The data collected were analyzed and presented using frequencies, numbers, mean \pm standard deviation and percentages.

\section{Results}

Forty-three patients' medical records were reviewed. Eight patients who did not meet study criteria were excluded from the study. Thirty-eight eyes of 35 patients were included the study. Twenty-six (74\%) of the patients were males and 9 (26\%) patients were females. Mean age was $31 \pm 19$ (1 to 78 ) years. A total of 38 injuries were studied. Twenty (53\%) injuries involved the right eye, 18 (47\%) involved the left eye. Three of the patients had bilateral injuries.

The most injuries were seen in two age groups; 10 years and under group and between 21-30 years old group. The age distribution of the patients is shown in Figure 2.

The main causes of ocular surgical injuries were traffic accidents in 15 eyes (39\%), work accidents in 11 eyes (29\%), assault in 5 eyes (13\%) and other causes in 7 eyes (18\%). Associated non-ocular trauma was presented in 4 eyes (11\%) and concomitant adnexa lesion was presented in 8 eyes (21\%).

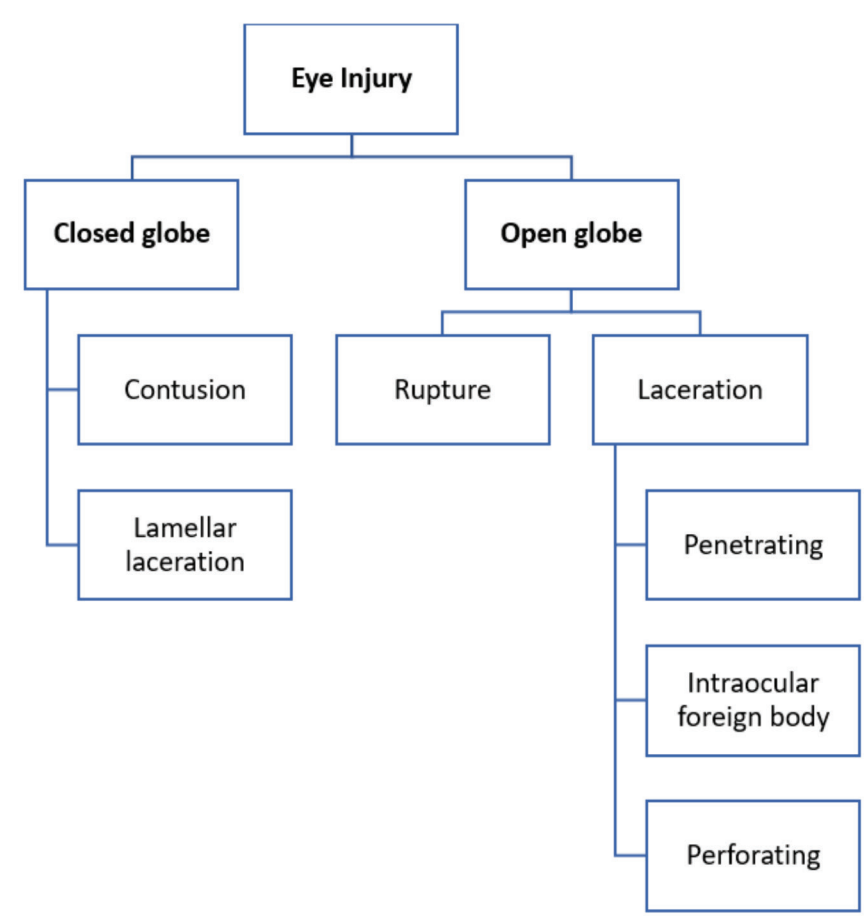

Figure 1. Birmingham Eye Trauma Terminology System classification of ocular injuries 
As for the classification of ocular trauma; 12 (32\%) were blunt trauma, 5 (13\%) were projectile (3 gun, 2 explosion), 11 (29\%) were sharp trauma and $10(26 \%)$ were others. The most frequent type of lesion was penetrating injury [22 eyes (58\%)].

Single disruption of either corneal or scleral penetration was present in 7 (18\%) and 4 (11\%) eyes, respectively. The most common concomitant ocular pathology was corneal-scleral penetration, which was presented in 8 (21\%) eyes. Other diagnosis included conjunctival laceration in 17 eyes (45\%), eyelid laceration in 11 eyes (29\%), and hyphema in 3 eyes (8\%). Mechanisms of injury with sharp objects were categorised into groups in Figure 3. The commonest type of injury was with metal tools. Intraocular foreign body (IOFB) is seen in 5 (13\%) eyes. All foreign bodies were located in the posterior segment. Context of IOFB was metallic in $2(40 \%)$ eyes, glass in $2(40 \%)$ eyes and biologic material in $1(20 \%)$ eye.

The surgical procedures performed are summarized in Table 1. The most common surgery was repairment of conjunctival laceration. [ $\mathrm{n}=17(45 \%)]$. Other surgeries were canalicul and lid margin repair (29\%), corneo-scleral reperation (21\%), corneal

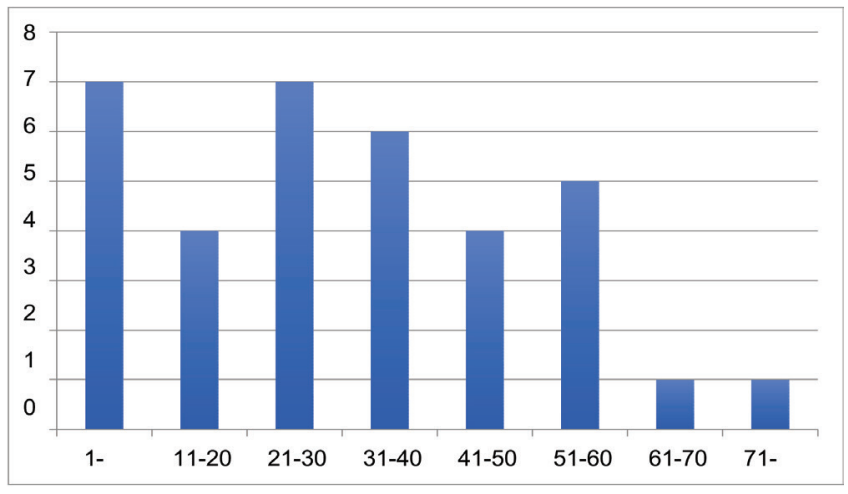

Figure 2. Distribution of patients age groups into 10-year interval

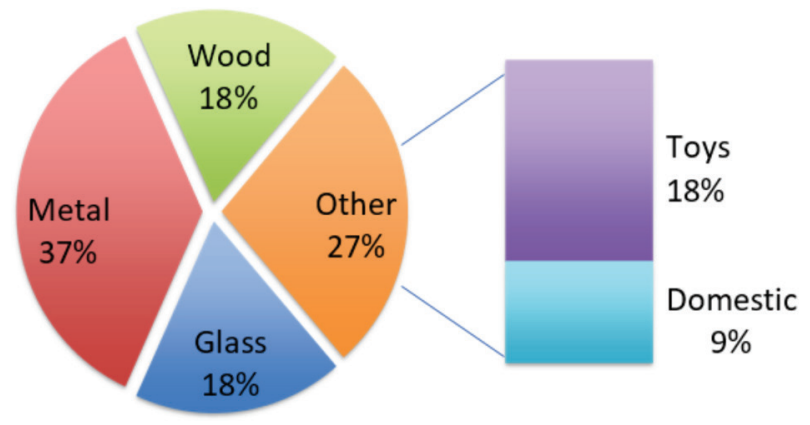

Figure 3. Mechanism of Injury with sharp objects reperation (18\%), scleral reperation (11\%) and anterior chamber irrigation (8\%) (Table 1).

In most eyes [ $\mathrm{n}=28(74 \%)]$, one surgery was sufficient, while 10 eyes $(26 \%)$ required two or more surgeries.

Most of the eyes $(n=33,86 \%)$ were operated on the first day of the injury. The others were operated between 1-10 days. Twenty (57\%) patients were hospitalized to ophthalmology service. Mean hospitalization duration was $5.25 \pm 3.2$ days (1-11). Other 15 (42\%) patients did not need hospitalization but were given medical treatment. After treatment had been provided, final BCVA was $1 / 10$ or worse in $10(26 \%)$ of the eyes. In nine eyes $(23 \%)$, final visual acuity was $9 / 10$ or better. BCVA increased in 19 eyes (50\%), while there was no change in 12 eyes (31\%) and decreased visual acuity in seven eyes (18\%) (Table 2).

\section{Discussion}

Previous studies showed that ocular trauma developed predominantly in males (72\%-90\%) and the young, with a majority under 30 years of age (12). Our study also showed a male dominancy with a majority in the third decade of life. It seems that the incidence and prevalence of ocular trauma between developed and developing countries are similar $(12,13)$.

The high-risk group is generally known to be between the ages of 15 and 64 years in males in the United States (13), and our results are in agreement.

Corneal tear, sclera tear and lens damage are the most frequently observed morbidities of ocular trauma followed by lid and canalicular laceration, uveal prolapse, anterior chamber abnormality, retinal detachment and optic nerve avulsion (14-16). The most frequent type of lesion, in our study, was

Table 1. Surgical procedures

\begin{tabular}{|l|l|}
\hline & Number of eyes (\%) \\
\hline Conjunctival suture & $17(45 \%)$ \\
\hline Canalicul/lid margin repair & $11(29 \%)$ \\
\hline Corneo-scleral suture & $8(21 \%)$ \\
\hline Corneal suture & $7(18 \%)$ \\
\hline Scleral suture & $4(11 \%)$ \\
\hline Anterior chamber irrigation & $3(8 \%)$ \\
\hline
\end{tabular}

Table 2. Changes in visual acuity

\begin{tabular}{|l|l|}
\hline Change in visual acuity & Number of eyes (\%) \\
\hline Improvement & $19(50 \%)$ \\
\hline No change & $12(31 \%)$ \\
\hline Worse & $7(18 \%)$ \\
\hline
\end{tabular}


penetrating injury (58\%) as similar. Single disruption of either corneal or scleral penetration was present in $18 \%$ and $11 \%$ of eyes, respectively.

The most common concomitant ocular pathology was cornealscleral penetration, which was presented in $21 \%$ of eyes. Other diagnosis included conjunctival laceration in 45\%, eyelid laceration in $29 \%$, and hyphema in $7 \%$ of eyes.

The previous studies have reported that primary lid-canalicular reconstruction and cornea-scleral suture were common surgical interventions in the emergency department for ocular injuries (17). In a study conducted in pediatric group, the most common mode of injury was wooden stick and the most common surgical intervention was cataract surgery with intraocular lens (18). In our study, the common mode of injury with sharp objects was metal and the common surgical interventions were conjunctival suture and cornea-scleral suture.

Since primary closure of eyelid can be performed directly in our emergency department by eye surgeon instead of operation room, our lid closure prevalence is less than expected.

A few studies from other countries have reported that about $3 \%-15 \%$ of patients required hospitalization $(19,20)$. Akdur et al. (21) stated that $49.4 \%(n=40)$ cases were hospitalized in ophthalmology service and surgical treatment was applied to $67.5 \%(n=27)$ of the hospitalized patients. According to our results, $20(57 \%)$ patients were hospitalized for operation. This difference in the incidence of hospitalization between previous studies and our study could be due to differences in the study size and distribution of the severe trauma cases. Because we see ocular traumas that require surgery more often because minor ocular traumas may be treated in other hospitals but especially severely injured ophthalmic patients usually come to our hospital.

In eyes with open globe injury, the most immediate question is the timing of wound closure. Thompson et al. (22) stated that the eyes undergoing surgical repair greater than 24 hours after the initial injury when compared with the eyes having primary repair within 24 hours, have a higher incidence of endophthalmitis. Kuhn and Slezakb (23) propose that in open-globe injuries, wound closure should be performed in the first 24 to 36 hours, as the risk of endophthalmitis does not measurably increase within this timing. In this study, surgical intervention was performed in the first 24 hours after admission in all open glob injuries.

We also preferred immediate surgery for open glob injuries but in case of IOFB, lid-canalicular reconstruction, cataract formation, we prefer to wait the other day for surgery, because vitreoretinal surgery and different surgical equipment may necessary.
Kutlutürk et al. (24) found the presence of foreign body $15.3 \%$ in the adult group and $5.1 \%$ in the pediatric group. AlMahmoud et al. (25) showed the percentage of IOFB was $21.3 \%$ in their study. Ozdamar Erol et al. (26) reported that all 14 patients with posterior segment IOFB and underwent vitrectomy were male and 12 of the foreign bodies were metallic, two were glass. In our study IOFB is seen in $5(13 \%)$ cases and all of them were located in the posterior segment. Context of IOFB was metallic in $2(40 \%)$ cases, glass in 2 (40\%) cases and biologic material in $1(20 \%)$ case. All cases with IOFB underwent vitrectomy within a week.

Our study has some limitations. First, due to its retrospective nature, there are not enough records of some epidemiological details (such as educational status, whether protective equipment is used or not). Second, it is single center study. Third; treatment of some minor traumas by family physicians before coming to the hospital or suturing some small incisions by emergency physicians may cause selection bias.

\section{Conclusion}

According to our study results, surgery-requiring ophthalmologic injuries involve mainly male at younger ages and traffic accidents are the most important cause of trauma. In $50 \%$ of these patients, an increase in visual acuity was observed after surgery so an early and correct surgery can prevent visual impairment and blindness.

\section{Ethics}

Ethics Committee Approval: This study was approved by Yıldırım Beyazıt University Faculty of Medicine Clinical Researches Ethics Committee (no:118, date: 28/05/2018).

Informed Consent: As this is a retrospective study, the participants' informed consent was not required.

Peer-review: Externally peer-reviewed.

\section{Author Contributions}

Concept: S.Y., Y.Y., Design: M.A.Y., Y.Y., Supervision: M.A.Y., Data Collection and/or Processing: S.Y., M.A.Y., Y.Y., Analysis and/or Interpretation: S.Y., M.A.Y., Literature Search: S.Y., Y.Y., Writing Manuscript: S.Y., M.A.Y., Critical Review: Y.Y.

Conflict of Interest: None of the authors have any conflicts of interest or any financial disclosures.

Financial Disclosure: This research did not receive any specific grant from funding agencies in the public, commercial, or notfor-profit sectors. 


\section{References}

1. Négrel AD, Thylefors B. The global impact of eye injuries. Ophthalmic Epidemiol. 1998;5:143-69.

2. Girard B. Activity and epidemiology Inanophthalmolocigal emergency center. J Fr Ophtalmol. 2002;25:701-11.

3. Meda N, Ouédraogo A, Daboué A, Ouédraogo M, Ramdé B, Somé D, et al. Etiologies des traumatismes oculo-palpébraux au Burkina Faso [Etiologies of ocular and eyelid trauma in Burkina Faso]. J Fr Ophtalmol. 2001;24:463-6.

4. Zagelbaum BM, Tostanoski JR, Kerner DJ, Hersh PS. Urban eye trauma. A oneyear prospective study. Ophthalmology. 1993;100:851-6.

5. Cao H, Li L, Zhang M, Li H. Epidemiology of pediatric ocular trauma in the Chaoshan Region, China, 2001-2010. PLoS One. 2018;8:60844.

6. Aghadoost D. Ocular trauma: an overview. Arch Trauma Res. 2014;3:21639.

7. Oner A, Kekec Z, Karakucuk S, Ikizceli I, Sözüer EM. Ocular trauma in Turkey: a 2-year prospective study. Adv Ther. 2006;23:274-83.

8. Durmus I. Evaluation of penetrative eye injuries in our clinic between 19761987. Kayseri, Turkey: Erciyes University; 1988.

9. Kuhn F, Morris R, Witherspoon CD, Heimann K, Jeffers JB, Treister G. A standardized classification of ocular trauma. Graefes Arch Clin Exp Ophthalmol. 1996;234:399-403.

10. Pieramici DJ, Sternberg P Jr, Aaberg TM Sr, Bridges WZ Jr, Capone A Jr, Cardillo JA, et al. A system for classifying mechanical injuries of the eye (globe). The Ocular Trauma Classification Group. Am J Ophthalmol. 1997;123:820-31.

11. Kuhn F, Morris R, Witherspoon CD, Mester V. The Birmingham Eye Trauma Terminology system (BETT). J Fr Ophtalmol. 2004;27:206-10.

12. Bejiga A. Causes and Visual Outcomes of Perforating Ocular Injuries among Ethiopian Patients. Community Eye Health. 2001;14:45-6.

13. Klopfer J, Tielsch JM, Vitale S, See LC, Canner JK. Ocular trauma in the United States. Eye injuries resulting in hospitalization, 1984 through 1987. Arch Ophthalmol. 1992;110:838-42.

14. Tejas D, Chinmayi V, Suhani D, Shiv M. Pattern of ocular injury in pediatric population in western India. NHL J Med Sci. 2013;2:37-40.
15. Jahangir T, Butt NH, Hamza U, Tayyab H, Jahangir S. Pattern of Presentation and Factors Leading to Ocular Trauma. Pak J Ophthalmol. 2011;27:96-102.

16. Alem KD, Arega DD, Weldegiorgis ST, Agaje BG, Tigneh EG. Profile of ocular trauma in patients presenting to the department of ophthalmology at Hawassa University: Retrospective study. PLoS One. 2019;14:0213893.

17. Lee KJ, Oh HJ. A Statistical Observation of the Ocular Injuries. J Korean Ophthalmol Soc. 1990;31:229-36.

18. Jain K, Jain A, Patil J, Gadiya T. Amblyopia therapy in children with penetrating corneal injuries. Taiwan J Ophthalmol. 2020;10:29-31.

19. Nash EA, Margo CE. Patterns of emergency department visits for disorders of the eye and ocular adnexa. Arch Ophthalmol. 1998;116:1222-6.

20. Dannenberg AL, Parver LM, Brechner RJ, Khoo L. Penetration eye injuries in the workplace. The National Eye Trauma System Registry. Arch Ophthalmol. 1992;110:843-8.

21. Akdur O, Özkan S, Erkılıç K, Durukan P, Duman A, íkizceli I. Evaluation of ocular trauma cases presenting to the emergency department. J Acad Emerg Med. 2009;8:47-50.

22. Thompson WS, Rubsamen PE, Flynn HW Jr, Schiffman J, Cousins SW. Endophthalmitis after penetrating trauma. Risk factors and visual acuity outcomes. Ophthalmology. 1995;102:1696-701.

23. Kuhn F, Slezakb Z. Damage control surgery in ocular traumatology. Injury. 2004;35:690-6

24. Kutlutürk Karagöz I, Söğütlü Sarı E, Kubaloğlu A, Elbay A, Çallı Ü, Pinero DP, et al. Characteristics of pediatric and adult cases with open globe injury and factors affecting visual outcomes: A retrospective analysis of 294 cases from Turkey. Ulus Travma Acil Cerrahi Derg. 2018;24:31-8.

25. AlMahmoud T, Al Hadhrami SM, Elhanan M, Alshamsi HN, Abu-Zidan FM. Epidemiology of eye injuries in a high-income developing country: An observational study. Medicine (Baltimore). 2019;98:16083.

26. Ozdamar Erol Y, Tekin K, Yilmazbas P. 23-gauge transconjunctival vitrectomy for posterior segment intraocular foreign bodies. Ulus Travma Acil Cerrahi Derg. 2019;25:298-302. 